\title{
Modern mating
}

Match point.

\begin{abstract}
John Zakour
Finally it was about to happen. All those hours in the lab, even more time invested searching, almost begging for grant money and backers, was about to pay off. A hundred years ago they had matchmakers. At the turn of century they had match-making websites. HA! Those were the dark ages! We were set to exponentially one-up them all with the very first custom made Perfect Android Mate, PAM-I.
\end{abstract}

Looking at her laying there on the lab table, she really was a sweet sight. Blonde hair draped over her shoulders, blue eyes with long curly lashes, perfectly chiselled button nose, a mouth with lips that were both pouty and sweet, and a body that had more curves than a road up the Alps. Every man would love to have her as his companion. And that's based on her looks alone.

But PAM-I is so much more than her appearance. Being programmable and customizable, we can make her whatever the end-user wants her to be. Her likes and interests can complement the user's perfectly. She gives new meaning to the term 'user-friendly'.

PAM-I was only the beginning! Once we had her up and running there would be other models of both sexes to follow. Yes sir, we were going to eliminate incompatibility and loneliness forever. I wasn't sure if I'd get a Nobel for this, but I was going to make a lot of cash.

Deb, my longest-serving postdoc, walked into the lab. Deb was a pleasant enough looking girl: short dark hair, friendly eyes; but she was no PAM-I. Then again, no flesh-and-blood woman was; they all came with their own likes and dislikes, their own mental baggage weighing them down. We were about to put an end to all that.

Deb looked PAM-I over from head to toe with a wary eye. "Dr Sebastian, are you sure about this?"

"Of course I'm sure. I have tenure!" I said.

She shook her head. "Man-made mates seem so unnatural." Deb considered herself my conscience.

Walking up and down the table bearing PAM-I, I gave her the last check-over. "This is 2077, we can do better than natural. The customer expects it."

Deb shook her head. "If you say so, I'm just a lowly postdoc."

"You've entered the last small-talk and useful trivia subroutines?” I asked.
Deb pulled out her small, paper-thin computer. She looked at it. "Yes."

I stroked PAM-I gently on the cheek; her skin was so soft. "You've alerted the press?"

She nodded. "Yes. Reps from all the major networks and blogs will be here in four hours." She hesitated. "Are you sure you want to show her to the press so soon? We haven't even done any beta testing yet."

I smiled at her. "I'll be doing the beta testing myself. After all, she is programmed to be my perfect match."

Deb lowered her head. "Are you really that forlorn?" she asked meekly.

I shrugged. It's true science can be a lonely mistress, especially when you're not the best-looking guy around. Humans can be so superficial. I couldn't admit that to one of my employees though. "No, no, of course not. Many scientists use themselves in experiments. Jung and Freud did it all the time. It's a prudent cost-cutting measure."

Deb rolled her eyes but I ignored her. I pointed to PAM-I. "Time to activate her!" I said dramatically.

Deb pushed a button on her computer.

"You are recording this for history," I reminded Deb.

"Of course," she sighed.

PAM-I shot up into a sitting position. She opened her eyes. "Where am I?" she asked.

"You are in New New York University artificial human lab-12," I told her.

"Oh," PAM-I said looking around. "Nice place."

"We're subsidized by Wal-Mart," Deb told her.

"So what's your favourite colour?" I asked PAM-I.

"Blue," she said.

"How many children would you like?" I asked.

"I can have children?"

"Yes, you are fully functional," Deb told her.

PAM-I smiled. "One girl, with red hair."
"Your favourite food?"

"Grilled shrimp with a touch of lime," she said.

"Who won the 1986 World Series?" I asked her.

"The Mets."

PAM-I was great. She was working out exactly as planned.

"What do you consider to be the perfect evening?" Deb asked.

PAM-I looked up at the ceiling thinking about her answer. She bit her lip and said: "Watching a ball game while giving my man a back rub and snacking on pizza."

Deb turned to me. "Yep, she's perfect for you."

"I know," I said barely able to contain my glee.

I held my hand out to PAM-I. She accepted it. I helped her to her feet. She took a step and stumbled. I caught her. She straightened up. "Sorry," she said. "Legs take a while to get used to."

"No problem," I said. I looked at my wrist computer. "We have three hours until I introduce you to the press."

"As your date?" she asked.

"Yes, that's the whole purpose of this operation," I said.

“To find you a date?" PAM-I asked, eyebrow raised.

"No, to make it so that everyone can have a perfect companion. You and I are the test pilots."

PAM-I looked at me with eyes wide open. She shook her head. "I don't like that."

Deb looked at me. "See, it's not right building an intelligent being for the sole purpose of being somebody's mate."

PAM-I shook her head again. "No, that's not what I mind at all...”

“Then what is it?" I asked.

"You're not nearly good looking enough for me," PAM-I told me.

Damn! We made her too human... John Zakour is a SF/humour writer with a master's degree in human behaviour. His last novel was The Frost-Haired Vixen (Daw, 2006). His next two novels will be The Blue-Haired Bombshell (Daw, 2007) and Baxter Moon Galactic Scout (Brown Barn, 2008). He can be found at www. johnzakour.com. 